\title{
(2) OPEN ACCESS \\ Ethnic and socioeconomic variation in cause-specific preterm infant mortality by gestational age at birth: national cohort study
}

\author{
Mary E Kroll, ${ }^{1}$ Jennifer J Kurinczuk, ${ }^{1}$ Jennifer Hollowell, ${ }^{1}$ Alison Macfarlane, ${ }^{2}$ \\ Yangmei Li (i) , ${ }^{1}$ Maria A Quigley ${ }^{1}$
}

\begin{abstract}
- Additional material is published online only. To view please visit the journal online (http://dx.doi.org/10.1136/ archdischild-2018-316463)
\end{abstract}

${ }^{1}$ Policy Research Unit in Maternal Health and Care, National Perinatal Epidemiology Unit, Nuffield Department of Population Health, University of Oxford, Oxford, UK

${ }^{2}$ Department of Midwifery, School of Health Sciences, City University, London, UK

Correspondence to Professor Maria A Quigley, Policy Research Unit in Maternal Health and Care, National Perinatal Epidemiology Unit, Nuffield Department of Population Health, University of Oxford, Oxford OX3 7LF, UK: maria.quigley@npeu.ox.ac.uk

Received 26 October 2018 Revised 8 April 2019 Accepted 12 April 2019 Published Online First 23 May 2019

\section{Linked}

- http://dx.doi.org/10.1136/ archdischild-2018-316418

\section{Check for updates}

(C) Author(s) (or their employer(s)) 2020. Re-use permitted under CC BY-NC. No commercial re-use. See rights and permissions. Published by BMJ.

To cite: Kroll ME, Kurinczuk J, Hollowell J, et al. Arch Dis Child Fetal Neonatal Ed 2020:105:F56-F63.

\section{ABSTRACT}

Objective To describe ethnic and socioeconomic variation in cause-specific infant mortality of preterm babies by gestational age at birth.

Design National birth cohort study.

Setting England and Wales 2006-2012.

Subjects Singleton live births at 24-36 completed weeks' gestation ( $n=256$ 142).

Outcome measures Adjusted rate ratios for death in infancy by cause (three groups), within categories of gestational age at birth (24-27, 28-31, 32-36 weeks), by baby's ethnicity (nine groups) or area deprivation score (Index of Multiple Deprivation quintiles).

Results Among 24-27 week births (5\% of subjects; $47 \%$ of those who died in infancy), all minority ethnic groups had lower risk of immaturity-related death than White British, the lowest rate ratios being $0.63(95 \% \mathrm{Cl}$ 0.49 to 0.80 ) for Black Caribbean, 0.74 (0.64 to 0.85) for Black African and 0.75 (0.60 to 0.94) for Indian. Among 32-36 week births, all minority groups had higher risk of death from congenital anomalies than White British, the highest rate ratios being 4.50 (3.78 to 5.37) for Pakistani, 2.89 (2.10 to 3.97) for Bangladeshi and 2.06 (1.59 to 2.68) for Black African; risks of death from congenital anomalies and combined rarer causes (infection, intrapartum conditions, SIDS and unclassified) increased with deprivation, the rate ratios comparing the most with the least deprived quintile being, respectively, 1.54 (1.22 to 1.93 ) and 2.05 (1.55 to 2.72). There was no evidence of socioeconomic variation in deaths from immaturity-related conditions.

Conclusions Gestation-specific preterm infant mortality shows contrasting ethnic patterns of death from immaturity-related conditions in extremely-preterm babies, and congenital anomalies in moderate/latepreterm babies. Socioeconomic variation derives from congenital anomalies and rarer causes in moderate/ late-preterm babies. Future research should examine biological origins of extremely preterm birth.

\section{INTRODUCTION}

Inequalities in infant mortality in England and Wales remain of concern, with relatively high risks in some Black and South Asian ethnic groups ${ }^{1}$ and for disadvantaged mothers. ${ }^{2}$ These inequalities reflect similar ethnic and socioeconomic variation in the occurrence of preterm birth, ${ }^{12}$ which is very closely associated with infant mortality. Preterm babies (under 37 weeks' gestation) constituted $8 \%$

\section{What is already known on this topic?}

- In England and Wales, most babies who die in infancy are born preterm.

- Patterns of infant mortality for preterm babies are poorly understood and may differ by level of prematurity.

\section{What this study adds?}

- In extremely preterm babies, risk of immaturityrelated death is lower for all minority ethnic groups than for White British.

- In moderate/late preterm babies, risk of death from congenital anomalies is higher for all minority ethnic groups than for White British and increases with deprivation.

- The study found no evidence of socioeconomic variation in deaths from immaturity-related conditions in any gestational age group.

of live births in England and Wales in 2015, but $72 \%$ of those who died in infancy. ${ }^{1}$

Whether there is also ethnic and socioeconomic variation in infant mortality specifically among preterm babies is not clear. Patterns of risk are poorly understood and may differ by degree of prematurity and cause of death. To our knowledge, no relevant gestation-specific analysis has examined different causes of death separately, and international evidence about gestation-specific all-cause mortality is limited by varying outcome definitions, gestation categories and ethnic groupings. ${ }^{3-15}$ The extent to which socioeconomic circumstances might contribute to ethnic variation in infant mortality, and vice versa, is uncertain.

We aimed to describe ethnic and socioeconomic variation in cause-specific infant mortality of singleton preterm babies in England and Wales by gestational age at birth.

\section{METHODS}

\section{Study design and data sources}

We conducted a national cohort study using routine data provided by the Office for National Statistics (ONS), based on National Health Service birth notifications linked with civil birth and death registrations. Details are reported elsewhere. ${ }^{16}$ The full 
cohort comprised all 4.7 million singleton babies born alive at $22+$ completed weeks of gestation in England and Wales from 1 January 2006 to 31 December 2012. We sequentially excluded births with implausible gestational age (43+ weeks), missing birth weight, or implausible birth weight for gestational age (more than twice the IQR above or below the median within sex-gestation-ethnicity strata of the dataset). We analysed the subset born at 24 to 36 completed weeks of gestation, applying the lower limit because of known variation in completeness of registration of births before 24 weeks. ${ }^{17}$

\section{Variables}

Using the ONS hierarchical classification based on The Tenth Revision of the International Statistical Classification of Diseases and Related Health Problems (ICD-10), ${ }^{18}$ we grouped the causes of infant death as congenital anomalies, immaturity-related conditions, and all other causes combined ('other'). Following WHO guidelines, ${ }^{19}$ we categorised gestational age at birth as 24-27 completed weeks (extremely preterm), 28-31 (very preterm) and 32-36 (moderate/late preterm). We grouped the baby's ethnicity (stated by the mother) as White British, White Non-British, Pakistani, Indian, Bangladeshi, Black African, Black Caribbean, other stated and unstated ${ }^{16}$; the 'other stated' group included categories that were mixed (eg, mixed White and Black Caribbean), rare (eg, Chinese) or non-specific (eg, 'any other Asian background'). We assessed socioeconomic disadvantage using quintile categories of the respective national Index of Multiple Deprivation (IMD) for England $2015^{20}$ and for Wales $2014,{ }^{21}$ based on the mother's address at birth registration. Gestational age was obtained from routine maternity records and is likely to have been based on the results of ultrasound examinations. $^{22}$ No data were available for other aspects of clinical care, such as the use of antenatal corticosteroids.

\section{Statistical analysis}

We conducted a separate analysis for each combination of gestation category and cause group, using Stata V.13 (StataCorp, 2013). Within gestation groups, we calculated cause-specific infant mortality rates per 1000 live singleton preterm births during 2006-2012, by ethnicity and by IMD quintile. To estimate the association of infant mortality with ethnicity, we fitted a Poisson regression model with robust standard errors, adjusting for potential confounding by birth year and gestation week (within gestation category) as continuous variables and for IMD as a categorical variable. To estimate the association with socioeconomic circumstances, we used IMD instead of ethnicity as the main exposure variable and included ethnicity instead of IMD among the adjustment factors. Causal diagrams for these models are presented in online supplementary figure $S 1 .{ }^{23}$ Variation in adjusted risk was measured by the appropriate Wald statistic, using a Bonferroni significance level of 0.0021 to compensate for multiple testing. ${ }^{24}$

\section{Sensitivity analysis}

We used IMD in our main analysis because this area-based measure of disadvantage was available for all members of the cohort. ONS applies the occupation-based National Statistics Socioeconomic Classification $^{25}$ (NS-SEC) to a $10 \%$ random sample of births. We refitted our socioeconomic model in this subgroup of the dataset to assess sensitivity to the socioeconomic measure used, replacing IMD with household NS-SEC (higher managerial, administrative and professional occupations; intermediate occupations; routine and manual occupations; other, including unstated/unspecific occupations, students, long-term unemployed and never worked).

\section{RESULTS}

\section{Descriptive analysis}

After exclusions for implausible gestational age (0.4\%), missing birth weight $(0.4 \%)$ and implausible birth weight $(1.5 \%)$, there were 4634932 live singleton births, ${ }^{16}$ of which 256142 were at 24-36 completed weeks of gestation (table 1). The proportion of births in the 'unstated' category of ethnicity was $6 \%$, decreasing from $10 \%$ in 2006 to $4 \%$ in 2012 . There were no other missing data.

Table 1 Characteristics of the study population

\begin{tabular}{|c|c|c|c|c|c|c|c|c|}
\hline \multirow{2}{*}{$\begin{array}{l}\text { Gestation at birth } \\
\text { Number of births }\end{array}$} & \multicolumn{2}{|c|}{ 24-27 weeks } & \multicolumn{2}{|c|}{ 28-31 weeks } & \multicolumn{2}{|c|}{$32-36$ weeks } & \multirow{2}{*}{$\begin{array}{l}\text { Total } \\
\mathrm{N}\end{array}$} & \multirow[b]{3}{*}{$\%$ IMD5 } \\
\hline & $\mathrm{N}$ & $\%$ & $\mathrm{~N}$ & $\%$ & $\mathrm{~N}$ & $\%$ & & \\
\hline Ethnicity & & & & & & & & \\
\hline White British & 6727 & 57.7 & 16852 & 63.2 & 141887 & 65.1 & 165466 & 28.4 \\
\hline White Non-British & 653 & 5.6 & 1436 & 5.4 & 13534 & 6.2 & 15623 & 27.5 \\
\hline Pakistani & 540 & 4.6 & 1200 & 4.5 & 8930 & 4.1 & 10670 & 56.0 \\
\hline Indian & 339 & 2.9 & 822 & 3.1 & 6749 & 3.1 & 7910 & 25.9 \\
\hline Bangladeshi & 141 & 1.2 & 340 & 1.3 & 3442 & 1.6 & 3923 & 58.2 \\
\hline Black African & 857 & 7.4 & 1348 & 5.1 & 7100 & 3.3 & 9305 & 49.7 \\
\hline Black Caribbean & 336 & 2.9 & 536 & 2.0 & 2934 & 1.4 & 3806 & 51.5 \\
\hline Other stated & 1231 & 10.6 & 2462 & 9.2 & 19707 & 9.1 & 23400 & 36.5 \\
\hline Unstated & 828 & 7.1 & 1691 & 6.3 & 13520 & 6.2 & 16039 & 26.9 \\
\hline IMD & & & & & & & & $\%$ WB \\
\hline $1=$ advantaged & 1229 & 10.5 & 3073 & 11.5 & 28256 & 13.0 & 32558 & 76.1 \\
\hline 2 & 1560 & 13.4 & 3697 & 13.9 & 32612 & 15.0 & 37869 & 73.4 \\
\hline 3 & 1921 & 16.5 & 4482 & 16.8 & 38534 & 17.7 & 44937 & 67.9 \\
\hline 4 & 2784 & 23.9 & 6504 & 24.4 & 50400 & 23.1 & 59688 & 59.2 \\
\hline $5=$ disadvantaged & 4158 & 35.7 & 8931 & 33.5 & 68001 & 31.2 & 81090 & 58.0 \\
\hline Total & 11652 & 100.0 & 26687 & 100.0 & 217803 & 100.0 & 256142 & 100.0 \\
\hline
\end{tabular}

Live singleton births at $24-36$ weeks, England and Wales $2006-2012$. Stratified by gestational age at birth (completed weeks).

IMD, Index of Multiple Deprivation; IMD5, most disadvantaged IMD quintile; N, number of births; WB, White British. 
Original article

Table 2 Number of infant deaths, by ethnicity and by area deprivation (IMD)

\begin{tabular}{|c|c|c|c|c|c|c|c|c|c|c|}
\hline \multirow{2}{*}{$\begin{array}{l}\text { Gestation at birth } \\
\text { Cause of death }\end{array}$} & \multicolumn{3}{|c|}{ 24-27 weeks } & \multicolumn{3}{|c|}{ 28-31 weeks } & \multicolumn{3}{|c|}{$32-36$ weeks } & \multirow[t]{2}{*}{ Total } \\
\hline & ConAnm & ImmRel & Other & ConAnm & ImmRel & Other & ConAnm & ImmRel & Other & \\
\hline \multicolumn{11}{|l|}{ Ethnicity } \\
\hline White British & 109 & 1522 & 206 & 213 & 442 & 166 & 553 & 146 & 488 & 3845 \\
\hline White Non-British & 18 & 124 & 28 & 28 & 49 & 16 & 67 & 15 & 33 & 378 \\
\hline Pakistani & 15 & 104 & 27 & 33 & 35 & 23 & 168 & 20 & 54 & 479 \\
\hline Indian/Bangladeshi & 8 & 86 & 15 & 23 & 28 & 11 & 88 & 8 & 28 & 295 \\
\hline Black African/Caribbean & 20 & 211 & 49 & 15 & 32 & 20 & 78 & 5 & 35 & 465 \\
\hline Other stated & 19 & 218 & 39 & 34 & 63 & 27 & 107 & 20 & 59 & 586 \\
\hline Unstated & 16 & 182 & 29 & 24 & 56 & 11 & 57 & 18 & 39 & 432 \\
\hline \multicolumn{11}{|l|}{ IMD } \\
\hline $1=$ advantaged & 14 & 260 & 43 & 35 & 89 & 14 & 91 & 26 & 60 & 632 \\
\hline 2 & 16 & 301 & 43 & 41 & 103 & 44 & 153 & 36 & 80 & 817 \\
\hline 3 & 32 & 409 & 70 & 56 & 113 & 45 & 159 & 36 & 107 & 1027 \\
\hline 4 & 52 & 613 & 82 & 92 & 164 & 73 & 267 & 56 & 187 & 1586 \\
\hline $5=$ disadvantaged & 91 & 864 & 155 & 146 & 236 & 98 & 448 & 78 & 302 & 2418 \\
\hline Total & 205 & 2447 & 393 & 370 & 705 & 274 & 1118 & 232 & 736 & 6480 \\
\hline$\%$ & 3 & 38 & 6 & 6 & 11 & 4 & 17 & 4 & 11 & 100 \\
\hline
\end{tabular}

Live singleton births at $24-36$ weeks, England and Wales $2006-2012$. Stratified by gestational age at birth (completed weeks) and cause of death. Ethnic groups with few deaths are combined to preserve confidentiality.

IMD, Index of Multiple Deprivation; ConAnm, congenital anomalies; ImmRel, immaturity-related.

The proportion of babies in the most disadvantaged IMD quintile (category 5) varied with ethnicity, being $26 \%$ to $28 \%$ for the Indian, White Non-British and White British groups but $50 \%$ to $58 \%$ for the Black African, Black Caribbean, Pakistani and Bangladeshi groups (table 1). The proportion of ethnic minority babies was higher for births at earlier gestational ages; in particular, the combined proportion of Black African and Black Caribbean babies increased from 5\% of births at 32-36 weeks to $10 \%$ of births at 24-27 weeks.

Overall, 6480 babies died in infancy (table 2), a rate of 25.3 per 1000 live singleton births at $24-36$ weeks; $52 \%$ of infant deaths were attributed to immaturity-related conditions, $26 \%$ to congenital anomalies and 22\% to other causes (postpartum infections $5 \%$, intrapartum asphyxia/anoxia/trauma $4 \%$, sudden infant death $3 \%$, antepartum infections $2 \%$ and unclassified $5 \%$ ). Births at 24-27 weeks constituted just 5\% of babies in the study population but $47 \%$ of those who died in infancy, while births at $32-36$ weeks constituted $85 \%$ of babies but $32 \%$ of those who died in infancy. Hence, crude all-cause infant mortality rates decreased from 261 per 1000 for births at 24-27 weeks to 10 per 1000 for births at 32-36 weeks (table 3).

\section{Ethnicity}

In babies born at 24-27 weeks, risk of immaturity-related death was low for the Black Caribbean (adjusted rate ratio 0.63), Black African (0.74), Indian (0.75), Pakistani (0.79) and White NonBritish (0.83) groups compared with White British $(\mathrm{p}<0.0001$ for ethnic variation) (table 4).

In babies born at 28-31 weeks, risk of death from congenital anomalies was high for the Pakistani (2.00), Bangladeshi (1.91) and White Non-British (1.53) groups, but low for the Black Caribbean group $(0.14)(\mathrm{p}=0.0008)$.

In babies born at 32-36weeks, risk of death from congenital anomalies was high for the Pakistani (4.50), Bangladeshi (2.89), Black African (2.06), Indian (1.79) and White Non-British (1.29) groups $(\mathrm{p}<0.0001)$.

There was no statistically significant ethnic variation in the other cause-gestation strata.

\section{Area deprivation}

In babies born at 32-36 weeks, risk of death from congenital anomalies was highest in the most disadvantaged IMD quintile (adjusted rate ratio 1.54 relative to the most advantaged) $(p=0.0009$ for variation between quintiles) (table 5). Risk of death from 'other' causes was highest in the most disadvantaged quintile $(2.05)(\mathrm{p}<0.0001)$ with an increasing trend.

There was no statistically significant variation between quintiles for any cause of death in babies born before 32 weeks or for immaturity-related death in any gestation category.

\section{Sensitivity analysis}

Although the NS-SEC analysis found no strong evidence of socioeconomic differences, the results were consistent with a socioeconomic trend in risk of death from 'other' causes in babies born at 32-36weeks (online supplementary table S1), as for the IMD analysis.

\section{DISCUSSION}

\section{Statement of principal findings}

Among live singletons born at 24-36 completed weeks' gestation, extremely preterm babies (24-27 weeks, $5 \%$ of the births) accounted for nearly half of infant deaths, very preterm babies (28-31 weeks, $10 \%)$ a fifth and moderate/late preterm babies (32-36 weeks, $85 \%)$ a third. Four-fifths of deaths were attributed to immaturity-related conditions or congenital anomalies.

Patterns of ethnic variation differed by gestational age at birth. Among extremely preterm babies, all minority ethnic groups had lower risk of immaturity-related death than White British, with adjusted rate ratios of $0.63-0.83$ for Black Caribbean, Black African, Indian, Pakistani and White Non-British. Among moderate/late preterm babies, all minority groups had higher risk of death from congenital anomalies than White British, with adjusted rate ratios of 4.5 for Pakistani, 2.9 for Bangladeshi and 2.1-1.2 for Black African, Indian and White Non-British. Patterns of ethnic variation for very preterm babies were intermediate. 
Table 3 Crude infant mortality rate per 1000 by ethnicity and by area deprivation (IMD), with $95 \% \mathrm{Cl}$

\begin{tabular}{|c|c|c|c|c|}
\hline Cause of death & Congenital anomalies & Immaturity-related & Other causes & All causes \\
\hline Gestation at birth & Rate per 1000 & Rate per 1000 & Rate per 1000 & Rate per 1000 \\
\hline 24-27 weeks & 17.6 (15.3 to 20.1$)$ & 210 (203 to 218$)$ & 33.7 (30.5 to 37.2 ) & 261 (253 to 269) \\
\hline \multicolumn{5}{|l|}{ Ethnicity } \\
\hline White British & 16.2 (13.3 to 19.5$)$ & 226 (216 to 236$)$ & 30.6 (26.6 to 35.0$)$ & 273 (262 to 284$)$ \\
\hline White Non-British & 27.6 (16.4 to 43.2 ) & 190 (161 to 222$)$ & 42.9 (28.7 to 61.4$)$ & 260 (227 to 296$)$ \\
\hline Pakistani & 27.8 (15.6 to 45.4$)$ & 193 (160 to 228$)$ & 50.0 (33.2 to 71.9$)$ & 270 (233 to 310$)$ \\
\hline Indian/Bangladeshi & 16.7 (7.22 to 32.6$)$ & 179 (146 to 216$)$ & $31.3(17.6$ to 51.0$)$ & 227 (190 to 267$)$ \\
\hline Black African/Caribbean & 16.8 (10.3 to 25.8$)$ & 177 (156 to 200$)$ & 41.1 (30.5 to 53.9 ) & 235 (211 to 260$)$ \\
\hline Other stated & 15.4 (9.32 to 24.0$)$ & 177 (156 to 200$)$ & 31.7 (22.6 to 43.1$)$ & 224 (201 to 249 ) \\
\hline Unstated & $19.3(11.1$ to 31.2$)$ & 220 (192 to 250$)$ & 35.0 (23.6 to 49.9$)$ & 274 (244 to 306 ) \\
\hline \multicolumn{5}{|l|}{ IMD } \\
\hline $1=$ advantaged & 11.4 (6.24 to 19.0$)$ & 212 (189 to 235$)$ & 35.0 (25.4 to 46.8$)$ & 258 (234 to 283 ) \\
\hline 2 & 10.3 (5.87 to 16.6$)$ & 193 (174 to 213 ) & $27.6(20.0$ to 37.0$)$ & 231 (210 to 252 ) \\
\hline 3 & 16.7 (11.4 to 23.4$)$ & 213 (195 to 232$)$ & 36.4 (28.5 to 45.8$)$ & 266 (246 to 286$)$ \\
\hline 4 & 18.7 (14.0 to 24.4$)$ & 220 (205 to 236$)$ & 29.5 (23.5 to 36.4$)$ & 268 (252 to 285$)$ \\
\hline $5=$ disadvantaged & 21.9 (17.7 to 26.8$)$ & 208 (196 to 220$)$ & 37.3 (31.7 to 43.5 ) & 267 (254 to 281$)$ \\
\hline 28- 31 weeks & $13.9(12.5$ to 15.3$)$ & 26.4 (24.5 to 28.4$)$ & 10.3 (9.09 to 11.6$)$ & 50.5 (48.0 to 53.2 ) \\
\hline \multicolumn{5}{|l|}{ Ethnicity } \\
\hline White British & $12.6(11.0$ to 14.4$)$ & 26.2 (23.9 to 28.8 ) & 9.85 (8.41 to 11.5$)$ & 48.7 (45.5 to 52.1$)$ \\
\hline White Non-British & 19.5 (13.0 to 28.1$)$ & 34.1 (25.3 to 44.9$)$ & 11.1 (6.38 to 18.0$)$ & 64.8 (52.6 to 78.8 ) \\
\hline Pakistani & 27.5 (19.0 to 38.4$)$ & 29.2 (20.4 to 40.3 ) & 19.2 (12.2 to 28.6$)$ & 75.8 (61.5 to 92.3 ) \\
\hline Indian/Bangladeshi & 19.8 (12.6 to 29.6$)$ & 24.1 (16.1 to 34.6$)$ & 9.47 (4.73 to 16.9$)$ & 53.4 (41.1 to 67.9$)$ \\
\hline Black African/Caribbean & 7.96 (4.46 to 13.1$)$ & 17.0 (11.6 to 23.9$)$ & 10.6 (6.50 to 16.3$)$ & 35.6 (27.7 to 44.9$)$ \\
\hline Other stated & 13.8 (9.58 to 19.2$)$ & 25.6 (19.7 to 32.6 ) & 11.0 (7.24 to 15.9$)$ & 50.4 (42.1 to 59.8 ) \\
\hline Unstated & 14.2 (9.11 to 21.0$)$ & 33.1 (25.1 to 42.8 ) & 6.51 (3.25 to 11.6$)$ & 53.8 (43.5 to 65.7$)$ \\
\hline \multicolumn{5}{|l|}{ IMD } \\
\hline $1=$ advantaged & 11.4 (7.95 to 15.8$)$ & $29.0(23.3$ to 35.5$)$ & 4.56 (2.49 to 7.63 ) & 44.9 (37.9 to 52.8 ) \\
\hline 2 & 11.1 (7.97 to 15.0$)$ & 27.9 (22.8 to 33.7$)$ & 11.9 (8.66 to 15.9$)$ & 50.9 (44.0 to 58.4$)$ \\
\hline 3 & 12.5 (9.45 to 16.2$)$ & 25.2 (20.8 to 30.2 ) & 10.0 (7.33 to 13.4$)$ & 47.7 (41.7 to 54.4$)$ \\
\hline 4 & 14.1 (11.4 to 17.3$)$ & 25.2 (21.5 to 29.3 ) & 11.2 (8.81 to 14.1$)$ & 50.6 (45.4 to 56.2 ) \\
\hline $5=$ disadvantaged & 16.4 (13.8 to 19.2$)$ & 26.4 (23.2 to 30.0$)$ & 11.0 (8.92 to 13.4$)$ & 53.7 (49.2 to 58.6$)$ \\
\hline 32-36 weeks & 5.13 (4.84 to 5.44$)$ & 1.07 (0.93 to 1.21$)$ & 3.38 (3.14 to 3.63 ) & 9.58 (9.17 to 10.0$)$ \\
\hline \multicolumn{5}{|l|}{ Ethnicity } \\
\hline White British & 3.90 (3.58 to 4.24$)$ & 1.03 (0.87 to 1.21$)$ & 3.44 (3.14 to 3.76 ) & 8.37 (7.90 to 8.85$)$ \\
\hline White Non-British & 4.95 (3.84 to 6.28$)$ & 1.11 (0.62 to 1.83$)$ & 2.44 (1.68 to 3.42 ) & 8.50 (7.02 to 10.2$)$ \\
\hline Pakistani & 18.8 (16.1 to 21.8$)$ & 2.24 (1.37 to 3.46 ) & 6.05 (4.55 to 7.88 ) & 27.1 (23.8 to 30.7$)$ \\
\hline Indian/Bangladeshi & 8.64 (6.93 to 10.6$)$ & 0.79 (0.34 to 1.55$)$ & 2.75 (1.83 to 3.97 ) & 12.2 (10.1 to 14.5$)$ \\
\hline Black African/Caribbean & 7.77 (6.15 to 9.69$)$ & 0.50 (0.16 to 1.16$)$ & 3.49 (2.43 to 4.85$)$ & 11.8 (9.74 to 14.1$)$ \\
\hline Other stated & 5.43 (4.45 to 6.56$)$ & 1.01 (0.62 to 1.57 ) & 2.99 (2.28 to 3.86 ) & 9.44 (8.14 to 10.9 ) \\
\hline Unstated & 4.22 (3.19 to 5.46$)$ & 1.33 (0.79 to 2.10$)$ & 2.88 (2.05 to 3.94 ) & $8.43(6.96$ to 10.1$)$ \\
\hline \multicolumn{5}{|l|}{ IMD } \\
\hline $1=$ advantaged & 3.22 (2.59 to 3.95$)$ & 0.92 (0.60 to 1.35$)$ & 2.12 (1.62 to 2.73 ) & 6.26 (5.38 to 7.25$)$ \\
\hline 2 & 4.69 (3.98 to 5.49 ) & 1.10 (0.77 to 1.53 ) & 2.45 (1.95 to 3.05 ) & 8.25 (7.30 to 9.29$)$ \\
\hline 3 & 4.13 (3.51 to 4.82 ) & 0.93 (0.65 to 1.29 ) & 2.78 (2.28 to 3.35 ) & 7.84 (6.98 to 8.77 ) \\
\hline 4 & 5.30 (4.68 to 5.97$)$ & 1.11 (0.84 to 1.44$)$ & 3.71 (3.20 to 4.28 ) & 10.1 (9.26 to 11.0$)$ \\
\hline $5=$ disadvantaged & 6.59 (5.99 to 7.23$)$ & 1.15 (0.91 to 1.43$)$ & 4.44 (3.96 to 4.97$)$ & 12.2 (11.4 to 13.0$)$ \\
\hline
\end{tabular}

Live singleton births at $24-36$ weeks, England and Wales $2006-2012$. Stratified by gestational age at birth (completed weeks) and cause of death. Ethnic groups with few deaths are combined to preserve confidentiality.

IMD, Index of Multiple Deprivation.

There was evidence of socioeconomic variation only for moderate/late preterm babies and for causes other than immaturityrelated conditions: risks of death from congenital anomalies and combined rarer causes (infections, intrapartum conditions, sudden infant death and unclassified) increased with area deprivation, adjusted rate ratios being 1.54 and 2.1, respectively, comparing the most with the least disadvantaged IMD quintile.

\section{Strengths and limitations}

To our knowledge, this is the first study to describe ethnic and socioeconomic variation in gestation-specific preterm infant mortality by cause of death. Some of our findings may be generalisable to similar ethnic and social groups resident in other countries. The study was based on linked routine data from England and Wales for a 7-year national birth cohort, with 
Original article

Table 4 Adjusted incidence rate ratio for infant mortality in preterm babies, by ethnicity relative to White British, with $95 \% \mathrm{Cl}$

\begin{tabular}{|c|c|c|c|c|}
\hline Cause of death & Congenital anomalies & Immaturity-related & Other causes & All causes \\
\hline \multicolumn{5}{|l|}{ Gestation at birth } \\
\hline \multicolumn{5}{|l|}{$24-27$ weeks } \\
\hline White British & 1.00 & 1.00 & 1.00 & 1.00 \\
\hline White Non-British & 1.66 (1.02 to 2.71$)$ & 0.83 (0.70 to 0.97$)$ & 1.44 (0.98 to 2.11$)$ & 0.94 (0.83 to 1.08$)$ \\
\hline Pakistani & 1.47 (0.86 to 2.50$)$ & 0.79 (0.67 to 0.94$)$ & 1.55 (1.04 to 2.29 ) & 0.92 (0.80 to 1.05$)$ \\
\hline Indian & 0.87 (0.36 to 2.11$)$ & 0.75 (0.60 to 0.94$)$ & 0.85 (0.44 to 1.65$)$ & 0.77 (0.64 to 0.93$)$ \\
\hline Bangladeshi & 1.15 (0.37 to 3.55$)$ & 0.77 (0.54 to 1.09$)$ & 1.43 (0.65 to 3.15$)$ & 0.87 (0.65 to 1.15$)$ \\
\hline Black African & 0.86 (0.49 to 1.50$)$ & 0.74 (0.64 to 0.85$)$ & 1.24 (0.87 to 1.77$)$ & 0.80 (0.71 to 0.90$)$ \\
\hline Black Caribbean & 0.94 (0.42 to 2.11$)$ & 0.63 (0.49 to 0.80$)$ & 1.30 (0.77 to 2.21$)$ & 0.72 (0.59 to 0.88$)$ \\
\hline Other stated & 0.88 (0.54 to 1.43 ) & 0.76 (0.67 to 0.86$)$ & 1.03 (0.73 to 1.44$)$ & 0.80 (0.72 to 0.89$)$ \\
\hline Unstated & 1.12 (0.67 to 1.88$)$ & 0.91 (0.80 to 1.03$)$ & 1.04 (0.71 to 1.54$)$ & 0.94 (0.84 to 1.05$)$ \\
\hline $\mathrm{X}^{2}$ for variation & $7.4, p=0.5$ & $53.0, p<0.0001$ & $9.3, p=0.3$ & $40.1, p<0.0001$ \\
\hline \multicolumn{5}{|l|}{ 28-31 weeks } \\
\hline White British & 1.00 & 1.00 & 1.00 & 1.00 \\
\hline White Non-British & 1.53 (1.03 to 2.26$)$ & 1.27 (0.95 to 1.69$)$ & 1.11 (0.67 to 1.86$)$ & 1.31 (1.06 to 1.60$)$ \\
\hline Pakistani & 2.00 (1.38 to 2.89$)$ & 1.11 (0.79 to 1.56$)$ & 1.82 (1.18 to 2.82 ) & 1.50 (1.21 to 1.85$)$ \\
\hline Indian & 1.32 (0.77 to 2.26$)$ & 0.72 (0.44 to 1.18$)$ & 0.95 (0.47 to 1.93$)$ & 0.92 (0.67 to 1.27 ) \\
\hline Bangladeshi & 1.91 (0.98 to 3.72 ) & 1.32 (0.75 to 2.34$)$ & 0.86 (0.28 to 2.68$)$ & 1.39 (0.94 to 2.06$)$ \\
\hline Black African & 0.76 (0.44 to 1.31$)$ & 0.56 (0.36 to 0.87$)$ & 0.90 (0.51 to 1.59 ) & 0.68 (0.51 to 0.91$)$ \\
\hline Black Caribbean & 0.14 (0.02 to 0.98$)$ & 0.75 (0.42 to 1.34$)$ & 1.21 (0.57 to 2.56$)$ & 0.68 (0.44 to 1.06$)$ \\
\hline Other stated & $1.06(0.74$ to 1.51$)$ & 0.95 (0.73 to 1.24$)$ & 1.07 (0.71 to 1.60$)$ & 1.00 (0.83 to 1.20$)$ \\
\hline Unstated & 1.12 (0.73 to 1.71$)$ & 1.26 (0.96 to 1.65$)$ & 0.63 (0.34 to 1.15$)$ & 1.09 (0.88 to 1.35$)$ \\
\hline $\mathrm{X}^{2}$ for variation & $26.7, p=0.0008$ & $17.1, p=0.03$ & $11.1, p=0.2$ & $35.0, p<0.0001$ \\
\hline \multicolumn{5}{|l|}{ 32-36 weeks } \\
\hline White British & 1.00 & 1.00 & 1.00 & 1.00 \\
\hline White Non-British & 1.29 (1.00 to 1.66$)$ & 1.16 (0.68 to 1.97$)$ & 0.71 (0.50 to 1.02 ) & 1.04 (0.86 to 1.25$)$ \\
\hline Pakistani & 4.50 (3.78 to 5.37$)$ & 2.13 (1.32 to 3.45$)$ & 1.49 (1.12 to 1.98$)$ & 2.93 (2.55 to 3.37 ) \\
\hline Indian & 1.79 (1.33 to 2.41$)$ & 1.02 (0.48 to 2.18$)$ & 0.85 (0.54 to 1.32$)$ & 1.30 (1.03 to 1.65$)$ \\
\hline Bangladeshi & 2.89 (2.10 to 3.97 ) & 0.29 (0.04 to 2.05$)$ & 0.57 (0.29 to 1.16$)$ & 1.59 (1.20 to 2.11$)$ \\
\hline Black African & 2.06 (1.59 to 2.68$)$ & 0.24 (0.06 to 0.97$)$ & 0.86 (0.57 to 1.29$)$ & 1.33 (1.07 to 1.65$)$ \\
\hline Black Caribbean & 1.20 (0.72 to 2.00$)$ & 0.91 (0.29 to 2.84$)$ & 0.83 (0.44 to 1.54$)$ & 1.01 (0.69 to 1.46$)$ \\
\hline Other stated & 1.36 (1.11 to 1.67$)$ & 0.98 (0.61 to 1.56$)$ & $0.82(0.62$ to 1.07$)$ & 1.09 (0.93 to 1.27$)$ \\
\hline Unstated & 1.08 (0.83 to 1.42$)$ & $1.20(0.73$ to 1.96$)$ & 0.81 (0.58 to 1.12$)$ & $0.99(0.82$ to 1.20$)$ \\
\hline $\mathrm{X}^{2}$ for variation & $308.7, p<0.0001$ & $16.7, p=0.03$ & $19.7, p=0.01$ & $238.8, p<0.0001$ \\
\hline
\end{tabular}

Live singleton births at $24-36$ weeks, England and Wales 2006-2012. Stratified by gestational age at birth (completed weeks) and cause of death. Adjusted for IMD, birth year and gestation week. All models have acceptable goodness-of fit (Pearson $p>0.1$ ). P-value from Wald test for ethnic variation shown in bold if statistically significant, with Bonferroni significance level 0.0021 to compensate for multiple tests.

IMD, Index of Multiple Deprivation.

virtually complete follow-up through the death registration system. Gestational age was derived from maternity records, and the proportion of exclusions for missing or implausible information was very small (2\%).

Where infant deaths were attributed to congenital anomalies, no information on the specific type of congenital anomaly was available. The study period (2006-2012) is now several years old, but the observed patterns of ethnic and socioeconomic variation seem likely to be reasonably stable over time. The proportion of births with unstated ethnicity decreased over time, from $10 \%$ in 2010 to $4 \%$ in 2016 , but all regression analyses were adjusted for potential confounding by birth year. Although birth notifications nominally recorded the baby's ethnicity as stated by the mother, in practice they may have included reports by healthcare professionals of the baby's or mother's ethnicity ${ }^{26}$; any resulting misclassification might have caused underestimation of differences between ethnic groups, but the potential bias is probably small. Area deprivation scores do not necessarily reflect individual socioeconomic circumstances; the sensitivity analysis using individual-level NS-SEC was underpowered, being based on just a 10\% sample of births, but gave compatible results. Using separate IMD quintiles for England and for Wales is unlikely to have materially affected the results, as deprivationspecific mortality rates are similar, ${ }^{27}$ and only $5 \%$ of the cohort were born to mothers resident in Wales.

\section{Relation to other findings}

Our results appear broadly consistent with international evidence on ethnic ${ }^{3-11}$ or socioeconomic ${ }^{12-15}$ variation in gestation-specific all-cause mortality of preterm babies. Comparisons require caution, however, as designs, settings, time periods, outcome definitions, gestation categories and ethnic groupings varied; births before 24 weeks and multiples were included; and maternal (not infant) ethnicity was generally examined. Some studies did not provide CIs or hypothesis tests, and none reported cause-specific risks. 
Table 5 Adjusted incidence rate ratio for infant mortality in preterm babies, by area deprivation (IMD quintile relative to $1=$ advantaged), with $95 \% \mathrm{Cl}$

\begin{tabular}{|c|c|c|c|c|}
\hline Cause of death & Congenital anomalies & Immaturity-related & Other causes & All causes \\
\hline \multicolumn{5}{|l|}{ Gestation at birth } \\
\hline \multicolumn{5}{|l|}{$24-27$ weeks } \\
\hline 2 & 0.89 (0.44 to 1.83$)$ & 0.92 (0.80 to 1.06$)$ & 0.77 (0.51 to 1.17$)$ & 0.90 (0.79 to 1.02 ) \\
\hline 3 & 1.45 (0.78 to 2.71$)$ & 1.01 (0.89 to 1.16 ) & 1.01 (0.69 to 1.46$)$ & 1.03 (0.92 to 1.16$)$ \\
\hline 4 & 1.61 (0.89 to 2.91 ) & 1.09 (0.96 to 1.23$)$ & 0.78 (0.55 to 1.13$)$ & 1.07 (0.96 to 1.19 ) \\
\hline \multicolumn{5}{|l|}{ 28-31 weeks } \\
\hline $1=$ advantaged & 1.00 & 1.00 & 1.00 & 1.00 \\
\hline 2 & 0.97 (0.62 to 1.52$)$ & 0.95 (0.72 to 1.25$)$ & 2.59 (1.42 to 4.71$)$ & 1.12 (0.90 to 1.39$)$ \\
\hline 3 & 1.08 (0.71 to 1.64$)$ & 0.85 (0.65 to 1.11$)$ & 2.13 (1.17 to 3.89$)$ & 1.04 (0.84 to 1.28$)$ \\
\hline 4 & 1.20 (0.81 to 1.78$)$ & 0.87 (0.67 to 1.12 ) & 2.36 (1.33 to 4.19$)$ & 1.10 (0.91 to 1.34$)$ \\
\hline $1=$ advantaged & 1.00 & 1.00 & 1.00 & 1.00 \\
\hline 2 & 1.41 (1.09 to 1.83$)$ & 1.18 (0.72 to 1.96$)$ & 1.16 (0.83 to 1.62$)$ & 1.30 (1.07 to 1.57$)$ \\
\hline 3 & $1.16(0.90$ to 1.50$)$ & 0.98 (0.59 to 1.62$)$ & 1.31 (0.95 to 1.80$)$ & 1.19 (0.99 to 1.43$)$ \\
\hline 4 & 1.35 (1.07 to 1.72$)$ & 1.18 (0.74 to 1.88$)$ & 1.76 (1.31 to 2.35$)$ & 1.46 (1.23 to 1.74$)$ \\
\hline $5=$ disadvantaged & 1.54 (1.22 to 1.93$)$ & 1.17 (0.75 to 1.83$)$ & 2.05 (1.55 to 2.72 ) & 1.65 (1.40 to 1.95$)$ \\
\hline $\mathrm{X}^{2}$ for variation & $18.8, p=0.0009$ & $1.4, p=0.8$ & $43.6, p<0.0001$ & $50.5, p<0.0001$ \\
\hline
\end{tabular}

Live singleton births at 24-36 weeks, England and Wales 2006-2012. Stratified by gestational age at birth (completed weeks) and cause of death. Adjusted for ethnicity (nine groups), birth year and gestation week. All models have acceptable goodness-of-fit (Pearson $\mathrm{p}>0.1$ ). P-value from Wald test for socioeconomic variation shown in bold if statistically significant, with Bonferroni significance level 0.0021 to compensate for multiple tests. IMD, Index of Multiple Deprivation.

In the UK in the 1990s, a relatively small hospital-based study found that neonatal mortality rates were similar for Black, South Asian and White mothers before 28 weeks, but lower for Black mothers than White among later preterm babies ${ }^{3}$; a larger hospital-based study found that perinatal mortality rates were lower for Black mothers than White before 32 weeks, but higher for Black than White thereafter and highest for babies of South Asian mothers at all preterm gestations. ${ }^{4}$ In the Netherlands during 1999-2007, national neonatal mortality rates for babies born at 26-31 weeks were higher for White mothers than African, South Asian, Mediterranean or East Asian. ${ }^{5}$ In the USA, national infant mortality rates until the early 2000 s were lower for Black mothers than White among extremely/ very preterm births and higher among later preterm births, ${ }^{67}$ but more recently were higher for Black mothers at all preterm gestations $^{8}$; other findings were similar. ${ }^{9-11}$

For England and Wales in 2005, national infant mortality rates within each preterm category were higher in households with routine/manual occupations than managerial/professional. ${ }^{12}$ Studies from France, Sweden and the Trent region of England found no evidence of socioeconomic variation in predischarge or infant mortality among births before 32 or 33 weeks, ${ }^{13-15}$ but a socioeconomic gradient in infant mortality for later preterm births. ${ }^{15}$

\section{Meaning of the study}

A population-based study in the Trent region of England found a socioeconomic gradient in incidence of birth at 22-32 weeks' gestation but not in subsequent survival, suggesting that deprivation was not a barrier to accessing and receiving effective neonatal care. $^{13}$ Our results for immaturity-related deaths confirm this finding in the national population and extend it to moderate/late preterm babies. Despite similar antenatal detection rates, women living in more deprived areas of the Trent region had lower rates of termination of pregnancy for major congenital anomalies than women in more affluent areas; this differential contributed to higher rates of birth with such anomalies and hence to higher rates of neonatal mortality. ${ }^{28}$ Similarly, for moderate/late preterm babies in the national population, we found that infant mortality from congenital anomalies was highest in the most disadvantaged group. We also found a socioeconomic trend in death from 'other' causes (including infections, intrapartum conditions and sudden infant death), but this is difficult to interpret, as the component causes will have different mechanisms and were too rare to analyse separately in our dataset.

Among moderate/late preterm babies, we found relatively high rates of death from congenital anomalies in the Pakistani and Bangladeshi groups (nearly five and three times the corresponding White British rate, respectively). Pakistani babies are known to have a relatively high incidence of congenital anomalies, particularly autosomal recessive conditions. ${ }^{29}$ Diabetes may play a role ${ }^{30}$ but it is generally accepted that the most important single cause is the high prevalence of endogamy and consanguineous marriage in some Pakistani communities ${ }^{29}$ : for example, in a recent study in Bradford UK, 59\% of 5127 Pakistani mothers were married to a blood relative. ${ }^{31}$ Accessibility or use of fetal anomaly screening may also contribute: limited evidence suggests that rates of prenatal diagnosis might be relatively low for South Asian women in the $\mathrm{UK}^{32}$ and attitudes to termination of pregnancy may vary. 
We found that the risk of immaturity-related death among extremely preterm babies was relatively low for Black and South Asian groups compared with White, despite their generally higher risks of preterm birth. ${ }^{16}$ We speculate that this apparently paradoxical observation might reflect variation between ethnic groups in the proportions of the many different biological causes of extremely preterm birth operating within those groups. For example, maternal sickle cell disease (SCD) ${ }^{33} 34$ incurs a risk of small fetal size and preterm delivery ${ }^{35} 36$ and will therefore contribute to the incidence of extremely preterm birth in the Black ethnic groups. The baby of a mother with SCD usually does not have SCD and may have no special problems after birth, other than immaturity. The spectrum of causes of extremely preterm delivery in babies of mothers without SCD will be slightly different, and may include a higher proportion of fetal conditions with serious postpartum implications. Maternal thalassaemia might provide a similar mechanism for South Asian babies. $^{33} 3437$

Ethnic variation in immaturity-related infant death is relevant to 'customisation' of the standards that support clinical decisions to induce labour for inappropriate fetal growth. ${ }^{38}$ Previous evidence that extremely preterm babies had better survival rates if their mothers were Black and that preterm births were more frequent in Black and South Asian families generated a hypothesis that the optimal period of gestation might be genetically shorter for Black and South Asian than White babies. ${ }^{39}$ The findings of our study are consistent with that hypothesis, but other explanations are possible (as discussed above, for example). A recent large international study on pregnancies of women with 'optimum health, nutrition, education and socioeconomic status' concluded that optimal fetal growth is similar in diverse geographical settings. ${ }^{40}$ This seems to imply that ethnic differences might be mediated either by disadvantage or by maternal ill-health. Our results suggest the latter should be considered.

\section{CONCLUSIONS}

Provision of neonatal care for preterm babies in England and Wales seems to be equitable, as we found no evidence of a socioeconomic gradient in gestation-specific risk of immaturityrelated death. Variations in prevalence of consanguineous marriage, uptake of fetal anomaly screening and attitudes to termination of pregnancy probably contribute to ethnic and socioeconomic variation in infant death from congenital anomalies. Among extremely preterm babies, risk of immaturity-related death is lower for Black and South Asian ethnic groups than for White, perhaps reflecting ethnic variation in the proportions of different causes of extremely preterm birth; future research should investigate potential biological mechanisms.

\section{Acknowledgements We thank Bliss, the Race Equality Foundation, Sands and the Lullaby Trust for their contributions to the Patient and Public Involvement (PPI) consultation for this study.}

Contributors $\mathrm{JH}$ conceived the study and all authors contributed to the design. Data acquisition was primarily conducted by $\mathrm{JH}$, and data cleaning and management by YL. Analyses were performed by MEK and supported by MAQ and JH. MEK drafted the initial manuscript and JJK, JH, AM and MAQ significantly contributed to revising it.

Funding This paper reports on an independent study that is funded by the NIHR Policy Research Programme in the Department of Health and Social Care (grant number 108/001).

Disclaimer The views expressed are not necessarily those of the Department.

Competing interests None declared.

Patient consent for publication Not required.
Ethics approval The study was approved by the National Research Ethics Service Committee South Central - Oxford B (reference 15/SC/0493)

Provenance and peer review Not commissioned; externally peer reviewed.

Data sharing statement The Office for National Statistics provided data for this study under an agreement which allows the data to be used only for the programme of infant mortality work of which this is a part

Open access This is an open access article distributed in accordance with the Creative Commons Attribution Non Commercial (CC BY-NC 4.0) license, which permits others to distribute, remix, adapt, build upon this work non-commercially, and license their derivative works on different terms, provided the original work is properly cited, appropriate credit is given, any changes made indicated, and the use is non-commercial. See: http://creativecommons.org/licenses/by-nc/4.0/.

\section{ORCID iD}

Yangmei Li http://orcid.org/0000-0001-5042-1151

\section{REFERENCES}

1 Office for National Statistics. Infant mortality (birth cohort) tables in England and Wales. 2018 https://www.ons.gov.uk/peoplepopulationandcommunity/birthsdeaths andmarriages/deaths/datasets/infantmortalitybirthcohorttablesinenglandandwales (accessed $11 \mathrm{Jul}$ 2018).

2 Weightman AL, Morgan HE, Shepherd MA, et al. Social inequality and infant health in the UK: systematic review and meta-analyses. BMJ Open 2012;2:e000964.

3 Lyon AJ, Clarkson P, Jeffrey I, et al. Effect of ethnic origin of mother on fetal outcome. Arch Dis Child Fetal Neonatal Ed 1994;70:F40-3.

4 Balchin I, Whittaker JC, Patel RR, et al. Racial variation in the association between gestational age and perinatal mortality: prospective study. BMJ 2007;334:833-5.

5 Schaaf JM, Mol BW, Abu-Hanna A, et al. Ethnic disparities in the risk of adverse neonatal outcome after spontaneous preterm birth. Acta Obstet Gynecol Scand 2012;91:1402-8.

6 Alexander GR, Wingate MS, Bader D, et al. The increasing racial disparity in infant mortality rates: composition and contributors to recent US trends. Am J Obstet Gynecol 2008; 198:51 e1-9.

7 Luke B, Brown MB. The changing risk of infant mortality by gestation, plurality, and race: 1989-1991 versus 1999-2001. Pediatrics 2006;118:2488-97.

8 Matthews TJ, MacDorman MF, Thoma ME. Infant Mortality Statistics From the 2013 Period Linked Birth/Infant Death Data Set. Nat/ Vital Stat Rep 2015;64:1-30.

9 King JP, Gazmararian JA, Shapiro-Mendoza CK. Disparities in mortality rates among US infants born late preterm or early term, 2003-2005. Matern Child Health J 2014; 18:233-41

10 Allen MC, Alexander GR, Tompkins ME, et al. Racial differences in temporal changes in newborn viability and survival by gestational age. Paediatr Perinat Epidemiol 2000;14:152-8.

11 Anderson JG, Rogers EE, Baer RJ, et al. Racial and Ethnic Disparities in Preterm Infant Mortality and Severe Morbidity: A Population-Based Study. Neonatology 2018;113:44-54.

12 Moser K, Macfarlane A, Chow YH, et al. Introducing new data on gestation-specific infant mortality among babies born in 2005 in England and Wales. Health Stat Q 2007;35:13-27.

13 Smith LK, Draper ES, Manktelow BN, et al. Socioeconomic inequalities in survival and provision of neonatal care: population based study of very preterm infants. BMJ 2009:339:b4702.

14 Bonet M, Smith LK, Pilkington $\mathrm{H}$, et al. Neighbourhood deprivation and very preterm birth in an English and French cohort. BMC Pregnancy Childbirth 2013;13:97.

15 Calling S, Li X, Sundquist J, et al. Socioeconomic inequalities and infant mortality of 46,470 preterm infants born in Sweden between 1992 and 2006. Paediatr Perinat Epidemiol 2011;25:357-65

16 Li Y, Quigley MA, Dattani N, et al. The contribution of gestational age, area deprivation and mother's country of birth to ethnic variations in infant mortality in England and Wales: A national cohort study using routinely collected data. PLOS One 2018;13:e0195146.

17 Smith L, Draper ES, Manktelow BN, et al. Comparing regional infant death rates: the influence of preterm births $<24$ weeks of gestation. Arch Dis Child Fetal Neonatal Ed 2013;98:F103-7.

18 Dattani N, Rowan S. Causes of neonatal deaths and stillbirths: a new hierarchical classification in ICD-10. Health Statistics Quarterly 2002:15.

19 World Health Organisation. Preterm Birth. https://www.who.int/news-room/factsheets/detail/preterm-birth (accessed Mar 2019).

20 Smith T, Noble M, Noble S, et al. The English Indices of Deprivation 2015. Technical Report. 2015 https://www.gov.uk/government/uploads/system/uploads/attachment_ data/file/464485/English_Indices_of_Deprivation_2015_-_Technical-Report.pdf (accessed Sept 2017).

21 Welsh Government. Welsh Index of Multiple Deprivation. 2014 http://gov.wales/ statistics-and-research/welsh-index-multiple-deprivation/?lang=en (accessed Sep 2017) 
22 Moser K, Hilder L. Assessing quality of NHS Numbers for Babies data and providing gestational age statistics. Health Stat Q 2008;37:15-23.

23 Textor J, Hardt J, Knüppel S. DAGitty: a graphical tool for analyzing causal diagrams. Epidemiology 2011;22:745.

24 Haynes W. Bonferroni correction. In: Dubitzky W, Wolkenhauer O, Cho K-H, eds. Encyclopedia of systems biology. New York, NY: Springer New York, 2013:154-54.

25 Office for National Statistics. The National Statistics Socio-Economic Classification (NS-SEC). https://www.ons.gov.uk/methodology/classificationsandstandards/ otherclassifications/thenationalstatisticssocioeconomicclassificationnssecrebasedonso c2010 (accessed Jan 2018).

26 Moser K, Stanfield KM, Leon DA. Birthweight and gestational age by ethnic group, England and Wales 2005: introducing new data on births. Health Stat $Q$ 2008:39:22-31.

27 Abel GA, Barclay ME, Payne RA. Adjusted indices of multiple deprivation to enable comparisons within and between constituent countries of the UK including an illustration using mortality rates. BMJ Open 2016;6:e012750.

28 Smith LK, Budd JL, Field DJ, et al. Socioeconomic inequalities in outcome of pregnancy and neonatal mortality associated with congenital anomalies: population based study. BMJ 2011:343:d4306.

29 Corry PC. Consanguinity and prevalence patterns of inherited disease in the UK Pakistani community. Hum Hered 2014;77:207-16.

30 Macintosh MC, Fleming KM, Bailey JA, et al. Perinatal mortality and congenital anomalies in babies of women with type 1 or type 2 diabetes in England, Wales, and Northern Ireland: population based study. BMJ 2006:333:177-77.

31 Sheridan E, Wright J, Small N, et al. Risk factors for congenital anomaly in a multiethnic birth cohort: an analysis of the Born in Bradford study. Lancet 2013;382:1350-9
$32 \mathrm{Yu}$ J. A systematic review of issues around antenatal screening and prenatal diagnostic testing for genetic disorders: women of Asian origin in western countries. Health Soc Care Community 2012;20:329-46.

33 Weatherall DJ, Clegg JB. Inherited haemoglobin disorders: an increasing global health problem. Bull World Health Organ 2001;79:704-12.

34 UK National Screening Committee. Sickle Cell and Thalassaemia Screening Programme. Data Report 2012/13: Trends and performance analysis. 2014 https:// www.gov.uk/government/uploads/system/uploads/attachment_data/file/410257/ Data_report_2012-13_-_Final_2_.pdf.

35 Oteng-Ntim E, Meeks D, Seed PT, et al. Adverse maternal and perinatal outcomes in pregnant women with sickle cell disease: systematic review and meta-analysis. Blood 2015:125:3316-25.

36 Oteng-Ntim E, Ayensah B, Knight M, et al. Pregnancy outcome in patients with sickle cell disease in the UK--a national cohort study comparing sickle cell anaemia (HbSS) with HbSC disease. Br J Haematol 2015;169:129-37.

37 Leung TY, Lao TT. Thalassaemia in pregnancy. Best Pract Res Clin Obstet Gynaecol 2012;26:37-51.

38 Stock SJ, Myers J. Defining abnormal fetal growth and perinatal risk: population or customized standards? PLoS Med 2017;14:e1002229.

39 Balchin I, Steer PJ. Race, prematurity and immaturity. Early Hum Dev 2007;83:749-54.

40 Villar J, Papageorghiou AT, Pang R, et al. The likeness of fetal growth and newborn size across non-isolated populations in the INTERGROWTH-21st Project: the Fetal Growth Longitudinal Study and Newborn Cross-Sectional Study. Lancet Diabetes Endocrinol 2014;2:781-92. 